\title{
Detection of Trichomonas vaginalis by different methods in women from Dohok province, Iraq
}

W.M. Al-Saeed ${ }^{7}$

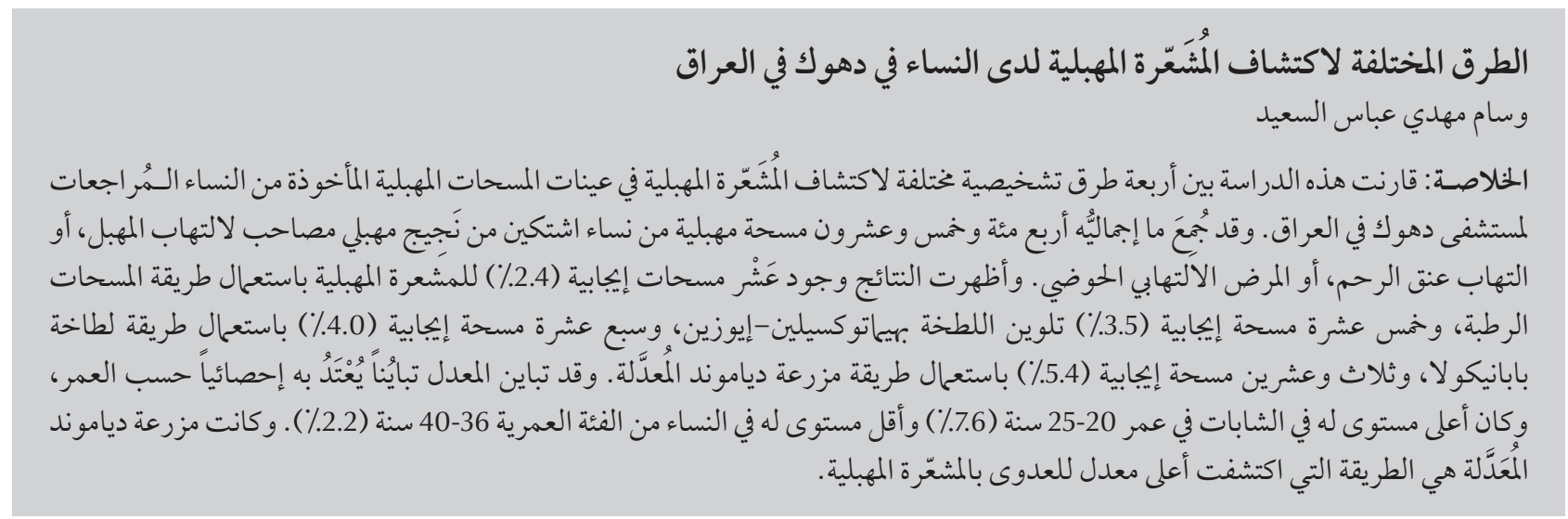

ABSTRACT This study compared 4 different diagnostic methods for the detection of Trichomonas vaginalis in vaginal swab specimens from women attending a hospital in Dohuk in Iraq. A total of 425 vaginal swabs were obtained from women complaining of vaginal discharge associated with vaginitis, cervicitis and pelvic inflammatory disease. The results showed that $10(2.4 \%)$ swabs were positive for $T$. vaginalis by wet smear preparation, 15 (3.5\%) by haematoxylin-eosin stained smear, 17 (4.0\%) by Papanicolaou stain and 23 (5.4\%) using Diamond modified culture. The rate varied significantly by age and was highest in young women aged 20-25 years $(7.6 \%)$ and lowest in the age group $36-40$ years $(2.2 \%)$. The highest rate of infection with $T$. vaginalis was detected by Diamond modified culture.

Dépistage de Trichomonas vaginalis par différentes méthodes chez des femmes de la province de Dahouk (Iraq)

RÉSUMÉ La présente étude a comparé quatre différentes méthodes diagnostiques pour le dépistage de Trichomonas vaginalis dans les prélèvements vaginaux de femmes consultant dans un hôpital de Dahouk (Iraq). Au total, 425 prélèvements ont été réalisés chez des femmes se plaignant de pertes vaginales associées à une vaginite, une cervicite ou une infection génitale haute. D’après les résultats, dix prélèvements (soit 2,4 \% d'entre eux) se sont révélés positifs pour T. vaginalis par la méthode des préparations humides, 15 (3,5\%) par la méthode de coloration à l'hématoxyline et l'éosine, 17 (4,0 \%) par la méthode de coloration de Papanicolaou et 23 (5,4\%) par la méthode de culture sur milieu de Diamond modifié. Le taux variait de manière significative en fonction de l'âge. Il était plus élevé chez les jeunes femmes âgées de 20 à 25 ans (7,6\%) et plus faible dans le groupe d'âge 36-40 ans (2,2\%). Le taux d'infection le plus élevé par T. vaginalis a été établi par la méthode de culture sur milieu de Diamond modifié. 


\section{Introduction}

Trichomonas vaginalis is a sexually transmitted, flagellated protozoan that causes vaginal infections in women, including vaginitis, urethritis and cervicitis [1]. T. vaginalis infections are not self-limiting and produce non-ulcerative inflammation of the genital epithelium that can progress to necrosis and haemorrhage $[2,3]$. Pregnant women infected with T. vaginalis may be at increased risk of premature labour, low-birth-weight offspring and postabortion or posthysterectomy infection [4-6].

It has been estimated that $10 \%$ to $50 \%$ of T. vaginalis infections in women are asymptomatic [7], and in men the proportion may even be higher. The most common tool for diagnosis of $T$. vaginalis infection is still microscopic examination of wet mount preparations, which has a sensitivity of approximately $60 \%$ [8]. Microscopic examination of cultures of the parasite in specialized media improves the sensitivity to $85 \%$ to $95 \%$ [9-11], The most sensitive of these media is thought to be modified Diamond medium $[9,10]$. Direct microscopic examination of vaginal secretions is the most common and rapid method used to diagnose trichomoniasis. Culture of vaginal and urethral specimens is the most sensitive, although slower, diagnostic technique $[11,12]$.

This study compared 4 different diagnostic methods for the detection of $T$. vaginalis in vaginal swab specimens obtained from women attending a hospital in Dohuk in Iraq.

\section{Methods}

\section{Sample and data collection}

The study sample was 425 female patients attending the department of gynaecology of Azadi hospital in Dohok province between October 2006 and June 2007 with complaints of vaginal and cervical infection. Two cotton swab specimens were obtained from the posterior vaginal fornix of all patients. The swabs were inserted into the pooled vaginal secretions touching both fornices and the middle third of the vaginal wall.

\section{Laboratory methods}

All swabs from the women were examined using 4 different laboratory methods. The first swab was used to produce a wet mount after mixing with normal saline for direct microscopic examination. Another 2 smears done from the first swab were fixed with $70 \%$ ethanol for further staining with Papanicolaou and haematoxylin-eosin stains $[13,14]$. A second swab specimen was immediately placed in $10 \mathrm{~mL}$ of Diamond modified medium (Becton Dickinson Microbiology Systems). This was prepared by dissolving $35 \mathrm{~g}$ of the powder media in $1 \mathrm{~L}$ distilled water, then bringing it to boiling point in order to dissolve the powder completely, then sterilization by autoclave at $121{ }^{\circ} \mathrm{C}$ for $15 \mathrm{~min}$. The medium was left to cool. The modification involved adding 50 $\mathrm{mL}$ of rice starch water and $50 \mathrm{~mL}$ of inactivated horse serum, then 1000 units of penicillin and $500 \mu \mathrm{g}$ of streptomycin and vancomycin were added to each $\mathrm{mL}$ of medium to inhibit the bacterial and fungal growth. Diamond modified medium was stored at $4{ }^{\circ} \mathrm{C}$ and allowed to reach room temperature prior to use. The vaginal swab was immersed in the newly prepared culture medium in bijou bottles under aseptic conditions (10-15 $\mathrm{mL}$ in each bottle), then incubated at $37^{\circ} \mathrm{C}$ for $72 \mathrm{~h}$.
Swabs were examined by wet mount microscopy.Microscopywasperformed at a magnification of $400 x$, and 20 fields were examined. Other unused media were stored at $4{ }^{\circ} \mathrm{C}$ until needed. Daily examination of culture for $3-5$ days by taking samples from the sediment or bottom of the vial culture were examined microscopically by wet mount for detection the Trichomonas spp. motility and activity. Smears stained with haematoxylin-eosin and Papanicolaou stains were examined under oil immer$\operatorname{sion}(1000 \times)$.

\section{Analysis}

The data were analysed using the chisquared and t-test to show the significance of any differences between those 4 diagnostic methods.

\section{Results}

Of 425 women complaining of vaginal secretions, vaginitis, cervicitis and pelvic inflammatory disease, 23 (5.4\%) showed the presence of $T$. vaginalis in the specimens examined by different diagnostic methods. T. vaginalis were detected in 10 (2.4\%) of the total by wet smear preparation, 15 (3.5\%) by haematoxylin-eosin stained smear, 17 (4\%) by Papanicolaou stain and 23 (5.4\%) in specimens cultured using modified Diamond culture method (Table 1).

Table 2 shows the frequencies of infection with T. vaginalis in different age groups and using different diagnostic methods. The rate varied significantly

Table 1 Frequency of detection of Trichomonas vaginalis infection in symptomatic women $(n=425)$ by 4 laboratory methods

\begin{tabular}{lcc} 
Test & $\begin{array}{c}\text { No. of infected } \\
\text { women }\end{array}$ & $\%$ \\
Wet smear & 10 & 2.4 \\
H\&E stain & 15 & 3.5 \\
Pap. stain & 17 & 4.0 \\
Modified Diamond culture & 23 & 5.4 \\
\hline
\end{tabular}

$H \& E=$ haematoxylin-eosin; Pap = Papanicolaou . 


\begin{tabular}{|c|c|c|c|c|c|c|c|}
\hline \multirow[t]{2}{*}{ Age (years) } & \multirow{2}{*}{$\begin{array}{c}\text { No. } \\
\text { examined }\end{array}$} & \multirow{2}{*}{$\begin{array}{c}\text { No. } \\
\text { infected }\end{array}$} & \multirow[t]{2}{*}{$\%$} & \multicolumn{4}{|c|}{ Test } \\
\hline & & & & Wet smear & H\&E stain & Pap. stain & $\begin{array}{c}\text { Modified } \\
\text { Diamond } \\
\text { culture }\end{array}$ \\
\hline $20-25$ & 92 & 7 & 7.6 & 4 & 5 & 4 & 7 \\
\hline $26-30$ & 88 & 6 & 6.8 & 3 & 4 & 5 & 6 \\
\hline $31-35$ & 78 & 5 & 6.4 & 5 & 4 & 5 & 5 \\
\hline $36-40$ & 93 & 2 & 2.2 & 2 & 1 & 0 & 2 \\
\hline $41-45$ & 74 & 3 & 4.1 & 2 & 2 & 2 & 3 \\
\hline \multirow[t]{2}{*}{ Total } & 425 & 23 & 5.4 & 16 & 16 & 16 & 23 \\
\hline & \multicolumn{3}{|c|}{$t=20.45, P<0.001$} & \multicolumn{4}{|c|}{$\chi^{2}=3.097, P=0.995$} \\
\hline
\end{tabular}

H\&E= haematoxylin-eosin; Pap. = Papanicolaou

by age and was highest in young women aged between $20-25$ years (7.6\%) and lowest in the age group 36-40 years (2.2\%).

\section{Discussion}

T. vaginalis infections are regarded as the most prevalent non-viral sexually-transmitted disease (STD) and are similar to other STDs in that the prevalence increases with increased numbers of sexual partners, presence of other STDs (especially gonorrhoea) and failure to use barrier contraceptives [12].

In the current study wet smear preparation detected the fewest number of infections with T. vaginalis (2.4\%), followed by haematoxylin-eosin stain (3.5\%) and Papanicolaou stain (4.0\%). The modified Diamond culture detected the highest rate of infection (5.4\% of specimens). In most settings the microscopic evaluation of vaginal discharge (wet preparation) has been the standard method used to diagnose T. vaginalis infections. The wet preparation is fast and convenient for clinicians and is inexpensive, but in asymptomatic women the sensitivity of the wet preparation in demonstrating motile trichomonads (definitive diagnosis) is only $60 \%$ to $80 \%$ [12]. Other stains, such as haematoxylin-eosin and $\mathrm{Pa}$ panicolaou have better sensitivities but are more labour-intensive and take time during processing of the stain and are moderately expensive [11]. Diamond's modified medium has been shown to be the most sensitive medium for the culture of T. vaginalis [9-11], possibly due to the starch content of the medium which gives similar environmental conditions as the vaginal epithelium [13]. However, the method needs as long as 3-7 days for confirmation of the diagnosis and is expensive when compared with previous methods.

Overall 5.4\% of women complaining of vaginal and cervical infection were found to be infected with $T$. vaginalis.
This rate is consistent with another study in Iraq, in Kirkuk (7.5\%) [14], but disagrees with similar studies done in Erbil (10\%) and in Mosul (14\%) $[15,16]$. The lower rate found in our study might be due to the women using vaginal washing and antiseptics after coitus with their partners or to the existence of health education programmes about STDs arranged by the maternal care office. The rates in this study and others in the Iraq, however, are lower than that reported in some other counties. The rate of infection in a hospital study New York city was reported as $41.3 \%$, and in a community study in South Africa as $41 \%[17]$.

The highest incidence of $T$. vaginalis was found in the age group 20-30 years, which is in agreement with Al-Samarrae's study in Iraq [18], and may be related to the greater sexual activity of this age group

In conclusion, the highest rate of infection with $T$. vaginalis was detected by Diamond modified culture.

\section{References}

1. Moodley $\mathrm{P}$ et al. Trichomonas vaginalis is associated with pelvic inflammatory disease in women infected with human immunodeficiency virus. Clinical Infectious Diseases, 2002, 34:519-522.

2. Viikki $\mathrm{M}$ et al. Gynaecological infections as risk determinants of subsequent cervical neoplasia. Acta Oncologica, 2000, 39:71-75.
3. Wasserheit JN. The interrelationship between human immunodeficiency virus infection and other sexually transmitted diseases. Sexually Transmitted Diseases, 1992, 19:61-77.

4. Swygard $\mathrm{H}$ et al. Trichomoniasis: clinical manifestation, diagnosis and management. Sexually Transmitted Infections, 2004, 80:91-95. 
5. Read JS, Lebanoff MA. Sexual intercourse during pregnancy and preterm delivery: effects of vaginal microorganisms. American Journal of Obstetrics and Gynecology, 1993, 168:514-519.

6. Viikki M E et al. Gynaecological infections as risk determinants of subsequent cervical neoplasia. Acta Oncologica, 2000, 39:71-75

7. Burstein GR, Zenilman JM. Nongonococcal urethritis a new aradigm. Clinical Infectious Diseases, 1999, 28 Suppl. 1;S66-S73.

8. Petrin D et al. Clinical and microbiological aspects of Trichomonas vaginalis. Clinical Microbiology Reviews, 1998, 11:300-317.

9. Gelbart SM et al. Growth of Trichomonas vaginalis in commercial culture media. Journal of Clinical Microbiology, 1990, 28:962-964.

10. Levi $\mathrm{MH}$ et al. Comparison of the InPouch TV culture system and Diamond's modified medium for detection of Trichomonas vaginalis. Journal of Clinical Microbiology, 1997, 35:3308-3310.

11. Wiese WS et al. A meta-analysis of the Papanicolaou smear and wet mount for the diagnosis of vaginal trichomoniasis. American Journal of Medicine, 2000, 108:301-308.

12. Heine $P$, McGregor R. Trichomonas vaginalis: a re-emerging pathogen. Clinical Obstetrics and Gynecology, 1993, 36:137-144.
13. Lawing LF, Hedges SR, Schwebke JR. Detection of trichomoniasis in vaginal and urine specimens from women by culture and PCR. Journal of Clinical Microbiology, 2000, 38:2585-2588.

14. Kadir MA, Jerjis KJ. Incidence of trichomoniasis in Kirkuk city. Journal of the Faculty of Medicine, Baghdad, 1999, 28(2):75-79.

15. Kadir MA, Salehy A, Hamed EE. Studies on Trichomonas vaginalis in Erbil teaching hospital. Journal of the Faculty of Medicine, Baghdad, 1996, 23(1):83-88.

16. Kharofa WA. An epidemiological study and cultivation of Trichomonas vaginalis in Mosul city [MSc thesis]. Department of Microbiology, College of Medicine, University of Mosul, Mosul, Iraq, 1999.

17. Sorvillo F, Smith L, Kerndt P. Trichomonas vaginalis, HIV and African-Americans. Emerging Infectious Diseases, 2001, 7:927932.

18. Al-Samarraie HF. Comparative study of Trichomonas vaginalis and bacterial coexistence in vaginal infection in pregnant and nonpregnant women [MSc thesis]. Department of Gynaecology and Obstetrics, College of Medicine, University of Baghdad. Baghdad, Iraq, 2002.

\section{Sexually Transmitted Diseases Diagnostics Initiative}

The Sexually Transmitted Diseases Diagnostics Initiative (SDI) was founded in 1990 in response to a widely-perceived need to improve care for patients with sexually transmitted infections (STIs) in resource-limited settings through improved diagnostics. It is estimated that $80 \%-90 \%$ of the global burden of STIs occurs in the developing world where there is limited or no access to diagnostics. SDI aims to promote the development, evaluation and application of diagnostic tests for STIs appropriate for use in primary health care settings in developing countries. Furth information about SDI can be found at: http://www.who.int/std_diagnostics/index.htm 